Research Article

\title{
Distribution of the Emergency Supplies in the COVID-19 Pandemic: A Cloud Computing Based Approach
}

\author{
Jixiao Wu $(\mathbb{D})$ and Yinghui Wang $\mathbb{D}$ \\ Department of Economics and Management, Shijiazhuang Tiedao University, Shijiazhuang 050043, China \\ Correspondence should be addressed to Yinghui Wang; wang112111@163.com
}

Received 16 August 2021; Revised 24 September 2021; Accepted 6 October 2021; Published 21 October 2021

Academic Editor: Dohyeong Kim

Copyright (C) 2021 Jixiao Wu and Yinghui Wang. This is an open access article distributed under the Creative Commons Attribution License, which permits unrestricted use, distribution, and reproduction in any medium, provided the original work is properly cited.

The containment of the COVID-19 pandemic was significantly affected by the unbalanced distribution of emergency supplies, low coordinated transport efficiency, high costs, and the inability of nonprofit organizations to handle the emergency supplies efficiently. Based on the COVID-19 experience, in this paper, we build a cloud platform for emergency supplies distribution to reduce the asymmetry of emergency logistics information, reduce the costs, and improve the efficiency of emergency supplies distribution. Our proposed method uses a genetic algorithm with the monarch scheme to optimize the urban emergency supplies distribution. The numerical results and sensitivity analysis for a sample network indicate that using the proposed platform the integrated cost in different cities are reduced by $29.01 \%, 28.67 \%$, and $22.73 \%$, the required time in different cities are reduced by $22.98 \%, 26.59 \%$, and $36.65 \%$. The results suggest that the proposed method reduces the integrated cost and transportation time and finds the optimal distribution path.

\section{Introduction}

The outbreak of COVID-19 at the beginning of 2020 resulted in a significant increase in demand for emergency supplies worldwide. This unprecedented situation severely affected the coordination of demand and supply due to inaccurate decision-making and inefficient distribution of emergency supplies. With the exponential increase in the number of confirmed COVID-19 patients, the existing emergency system became quickly ineffective. This resulted in the shortage of vital emergency supplies in some affected regions, caused significant pressure on the emergency workers, and further aggravated the difficulty of containing the spread of the COVID-19 epidemic.

The emergency services in the epidemic are defined by the National Disaster Medical System (NDMS) as the set of urgent healthcare or medical services required in response to significant/catastrophic incidents, such as natural disasters, significant outbreaks of infectious diseases, and bioterrorist attacks [1]. Although epidemics inevitably happen, their spread can be effectively contained by building an effective emergency logistics system. This paper proposes a cloud computing-based platform to incorporate Big Data, informatization, and intelligence to address the emergency supplies distribution problem in the affected regions. Our objective is to optimize the distribution of emergency supplies to accelerate epidemic relief. Our approach is to integrate the supply and demand information of the emergency supplies on the cloud platform. This reduces the opacity of this information in the emergency logistics services, the asymmetry of supply and demand cat egories, and the uncertainty of distribution. Using the cloud platform, the Big Data, including the emergency supplies, demand points, distribution vehicles and supply, and demand information of different emergency supplies, are processed. The cloud platform then uses these data to optimize the connection of each node in the emergency logistics network while effectively reducing the cost of emergency logistics. This approach enables efficient and intelligent emergency supplies distribution.

Emergency logistics is referred to the logistics service that responds to disasters (e.g., H1N1 influenza, SARS virus, Ebola virus, earthquake, and terrorist attack) [1]. To optimize the distribution of the supplies within the required 
time-frame in the emergency logistics, various technologies are used, for example, system dynamics [2], heuristic algorithm [3-7], and Internet of Things technology [8]. In the existing works, the optimization of emergency logistics is mainly focused on time [9-11] and cost [6, 12-15]. However, the distribution of supplies for COVID-19 is different from the traditional emergency logistics and has unique features [16]. We incorporate the unique features of the disaster demand points in COVID-19 [16] and adopt a genetic algorithm to optimize the emergency supplies distribution subject to time constraints.

With the development of information technology, information technology has been widely used to improve the logistics process, realizing the logistics informatization from the network to the client. For instance, logistics alliances [17], hyper-network theory [18], and other methods are adopted to combine emergency supply chains to optimize logistics services. Such techniques are based on constructing a comprehensive emergency supplies distribution platform to solve the multipath problem in logistics networks [18-21]. Big Data plays an essential role in the auxiliary resource scheduling and prevention decision-making of the epidemic. Furthermore, the application of intelligent logistics systems effectively improves the resilience of cities in responding to epidemics [22-24]. Therefore, establishing a unified transporting and coordination mechanism for the emergency supply chain eliminates the imbalance in the supply of supplies and satisfies the demand for medical treatments [25]. New technologies such as blockchain are also used in designing efficient emergency supply chains. For instance, blockchain technology is used to build an information management model of supply for targeted donation and epidemic prevention supplies, which shows that using blockchain technology improves the performance of emergency logistics in terms of information transparency, credibility, efficiency, and fairness. Furthermore, it enables efficient coordination of emergency supplies supply [26]. The aforementioned research provides significant supporting evidence that the combination of emergency logistics with advanced information technologies, such as blockchain and cloud computing platforms, plays a pivotal role in the efficient design of such systems. Nevertheless, the current literature has not thoroughly investigated the model build and function design of logistics informatization. The build of logistics information platforms in emergency disasters (especially the COVID-19 epidemic) is still rare. So we have combined the supplies demand features of COVID-19 to build an emergency logistics cloud platform.

Furthermore, in some existing works, a combination of cloud computing and logistics is used to an intelligent logistics system based on logistics informatization [27]. Furthermore, in Govindan et al.'s study [23], the benefits of integrating Big Data and cloud technology into the logistics supply chain are investigated. The build of the emergency logistics cloud platform can rely on government departments [28]. The risks associated with network security, user acceptance, information technology updates, and data sharing in the logistics information platforms are managed by devising a ladder risk management mechanism and optimizes the logistics cloud platform's data sharing and information security capabilities [29]. Also, in Lijia's study [30], considering the automatic matching based on the cloud technology functions formulated the optimal dynamic coordination among the users as a multiobjective optimization problem. It is also shown by $\mathrm{Fu}$ et al. [31] that cloud technology can optimize the distribution efficiency of the emergency logistics network. Nevertheless, the existing works seldom combine the cloud platform with emergency logistics and rarely realize the efficiency improvement of emergency supplies distribution through the cloud platform. To strengthen the range of the cloud platform and improve the distribution efficiency of emergency supplies, we combine the cloud platform with emergency logistics, design an emergency logistics cloud platform in COVID-19, and improve the functions of the cloud platform.

Recently, some technologies are used in a wide range of intelligent management applications for sustainability, but these methods are rarely used in human space networks for public health. Based on the previous research, the objective of this paper is to optimize the urban emergency supplies distribution plan by the cloud platform. This paper's contributions are as follows. (1) We build a cloud platform to solve the inefficiency of the supply distribution, low distribution efficiency, and high transaction costs caused by information asymmetry in emergency logistics. (2) The proposed cloud platform optimizes the urban emergency supplies distribution routes, ensures the timeliness of emergency supplies, and reduces the cost of emergency supplies.

\section{Emergency Supplies Distribution Design Based on a Cloud Platform}

According to the "Trust Report: Cloud Computing in China" jointly released by Alibaba Cloud, IEEE China, and Alibaba Research Institute in 2018, more than 70\% of companies have transferred more than half of their businesses to a cloud computing platform. The report also points out that about $43 \%$ of companies transferred all their businesses to a cloud computing platform. This report concludes that using cloud computing platforms has become a norm that the Chinese business community has accepted. Based on the existing research on Big Data and informatization in emergency logistics [32-34], we built a cloud computing platform for emergency supplies distribution in the epidemic. Compared with the supply distribution model built in the existing literature, this research adopts the cloud computing platform to handle multiple supply and demand information. We then formulate the optimal supplies distribution plan according to the demand for supplies in different epidemic areas. Big Data and cloud computing have been applied to general logistics in intelligent logistics, solving optimization problems, supply chain management, transportation path planning, and supplies distribution [35]. The supply distribution model based on the cloud platform relies on cloud computing, Big Data technology, communication facilities, and various servers and network facilities. The cloud platforms also have unified technical standards, system settings, 
and protocol specifications [30]. With the Internet as the key, the cloud platform integrates subsystems to form intelligent and complex decision-making systems with various functions and modules [30]. The proposed emergency supplies distribution cloud platform (see Figure 1) comprises an emergency logistics system, a vehicle distribution system, an emergency supplies system, and a core module. In the following, we explain the module's functions and elaborate on the data relationship and transmission routes between them.

The emergency logistics system connects the supply requirements of each node to the cloud platform and penetrates each link of the transport. The vehicle distribution system also optimizes the cloud platform supplies distribution model in terms of the information and service flows. The system also integrates the logistics, capital, and information flow involved in the entire supply chain into the emergency supplies distribution cloud platform. Internet of Things is also used to monitor logistics and transport in realtime. The emergency supplies system combines the emergency supplies provided by various suppliers with the cloud platform to strengthen the supervision of emergency supplies by nonprofit organizations. The core module is composed of 4 parts: communication layer, isolation layer, cloud computing, and Big Data. This module quickly integrates the supply-demand information of the emergency logistics cloud platform and feedback to each node in time and effectively [36]. This results in inefficient operation of the logistics network, reasonable distribution of the supplies, and optimizing the logistics costs.

The core module of the cloud platform consists of four parts: communication layer, isolation layer, cloud computing, and Big Data. The communication layer uses the wired communication based on optical cable, metal wire, and wireless communication to transmit the data information of the vehicles, supplies demand, and supplies inventory provided by each node. The isolation layer is to ensure data security. The isolation method mainly comprises network isolation with firewalls between internal and external source networks and data isolation with encryption technology [37]. Cloud computing is then used to store a massive amount of data, which are also classified and analyzed. The processing of big data includes performing secondary mining on the data to filter out the critical information, processing the filtered critical information through intelligent algorithms, and combining the actual demand information to analyze the optimal supply distribution method. The decision information is then transmitted to the nodes through the communication layer and fed back to the actual logistics transport process.

Based on the aforementioned framework and combined with the epidemic prevention requirements of COVID-19, this paper builds an emergency supplies distribution auxiliary system in COVID-19 based on the existing GuangDong Platform for Common GeoSptial Information Services (http://guangdong.tianditu.gov.cn/). The functional structure of the system is shown in Figure 2. It includes a public service system, epidemic prevention and control system, mobile service system, postepidemic decision auxiliary system, departmental coordination system, emergency supplies management system, shared exchange system, and interface services with other systems [38]. The system can be quickly built based on the services provided by the GuangDong Platform for Common GeoSptial Information Services.

The collaboration model between the emergency supplies distribution system and the auxiliary system based on the cloud platform in the COVID-19 is shown in Figure 3.

The system design and key technologies of emergency supplies distribution on the cloud platform are as follows.

2.1. Unified Data Management and Sharing Service. Based on the unified data management provided by the cloud platform and hierarchical sharing services for emergency demand, the hierarchical management of epidemic prevention and control can be quickly realized. It can complete hierarchical prevention and control management at the city, district, and town levels.

2.2. Place Name and Address Matching Service. Based on the place name and address matching service provided by the cloud platform, the rapid mapping of various types of epidemic data is realized, and the epidemic prevention and control map is formed promptly.

2.3. Intelligent Algorithm Service. Through intelligent algorithms combined with urban population data, the distribution of floating populations in high-risk areas can also be analyzed. This facilitates targeted epidemic prevention and control. The intelligent algorithm service of the cloud platform is mainly reflected in the following aspects:

(i) Build a distributed spatiotemporal big data storage engine, which uses NoSQL and SQL combination and is compatible with HBase, Hadoop, and PostgreSQL to realize the organization and management of large-scale heterogeneous spatiotemporal data.

(ii) Establish a distributed spatiotemporal Big Data index, support multiple indexes, such as R-Tree and GeoHash, which used distributed GIS algorithm and combined with Spark cluster to provide largescale distributed memory computing.

(iii) Integrate GPU/CPU large-scale parallel computing to provide high-performance Web-based GIS computing services.

2.4. Public Service Platform. The public service platform can help the construction of an emergency logistics system. For example, Guangdong Province has met the demand of different departments and people for data by building the GuangDong Platform for Common GeoSptial Information Services, realized various demands from "zero-code" construction to complex secondary development. 


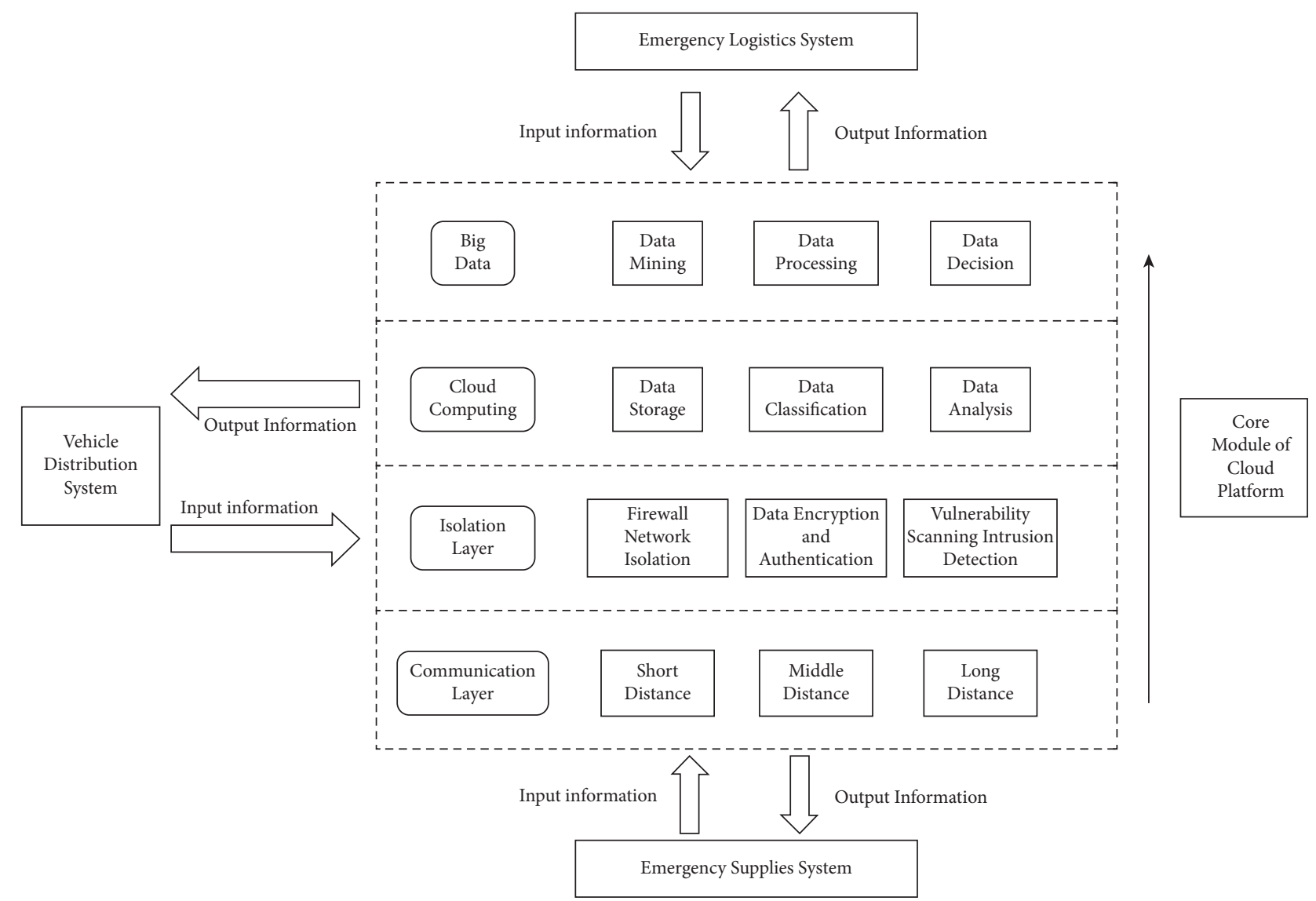

FIGURE 1: The framework of the emergency supplies distribution of the proposed cloud platform.

2.5. Meet Multilevel Demands. The construction of the emergency logistics system should consider the use of CDC, hospitals, medical institutions, and other government departments and consider the use of the public.

The special distribution centers should handle the distribution of emergency supplies. The transport reserve system is different from the general supplies for the supply of emergency supplies in terms of financing, reserve, and transport [39]. To clarify the modelling boundaries, this research obtains emergency supplies supply information and classifies the demand information through the cloud platform, focusing on emergency supplies distribution. The emergency supplies distribution steps of the cloud platform can be briefly summarized as follows: publish supplies demand data at various demand points $\longrightarrow$ collect the emergency supplies from suppliers and distribution centers in various places $\longrightarrow$ supplies reserve and distribution plan $\longrightarrow$ intelligent cloud decisionmaking for supplies sorting, vehicle management, and path selection $\longrightarrow$ supplies distribution at each demand point. The detailed flowchart of the proposed emergency supplies distribution is presented in Figure 4 . The cloud platform is mainly responsible for the information flow part, and the logistics part is handed over to the relevant emergency personnel.

\section{Methods}

The emergency supplies are demanded during the incident, and after a major epidemic, the emergency supplies reserved in the city become low. Hence, the reserves are not sufficient for the long-term needs of the city's emergency. Note that the demand of each demand point in the epidemic and their urgency might be different. Therefore, it is essential to reasonably plan the supply distribution to fluctuation emergency supplies' demands. The existing supply chain of emergency supplies is generally a 3-level distribution network of "supplies, supplier-distribution centers, and demand points" as shown in Figure 5. However, such patterns require more data and excessively make unrealistic assumptions on time spent in the parts [40].

The traditional distribution model of emergency supplies has complicated processes and insufficient information communication between nodes. This is also prone to a lot of additional costs. The distribution model of emergency supplies based on the cloud platform (as shown in Figure 6) can optimize the " $i * j$ " routes between the suppliers, $i$, and the demand points $j$ to " $i+j$ " routes by the cloud platform, which greatly simplifies the distribution process. Sufficient sharing of information resources enabled by the cloud platform enables the supplier to fully understand the 


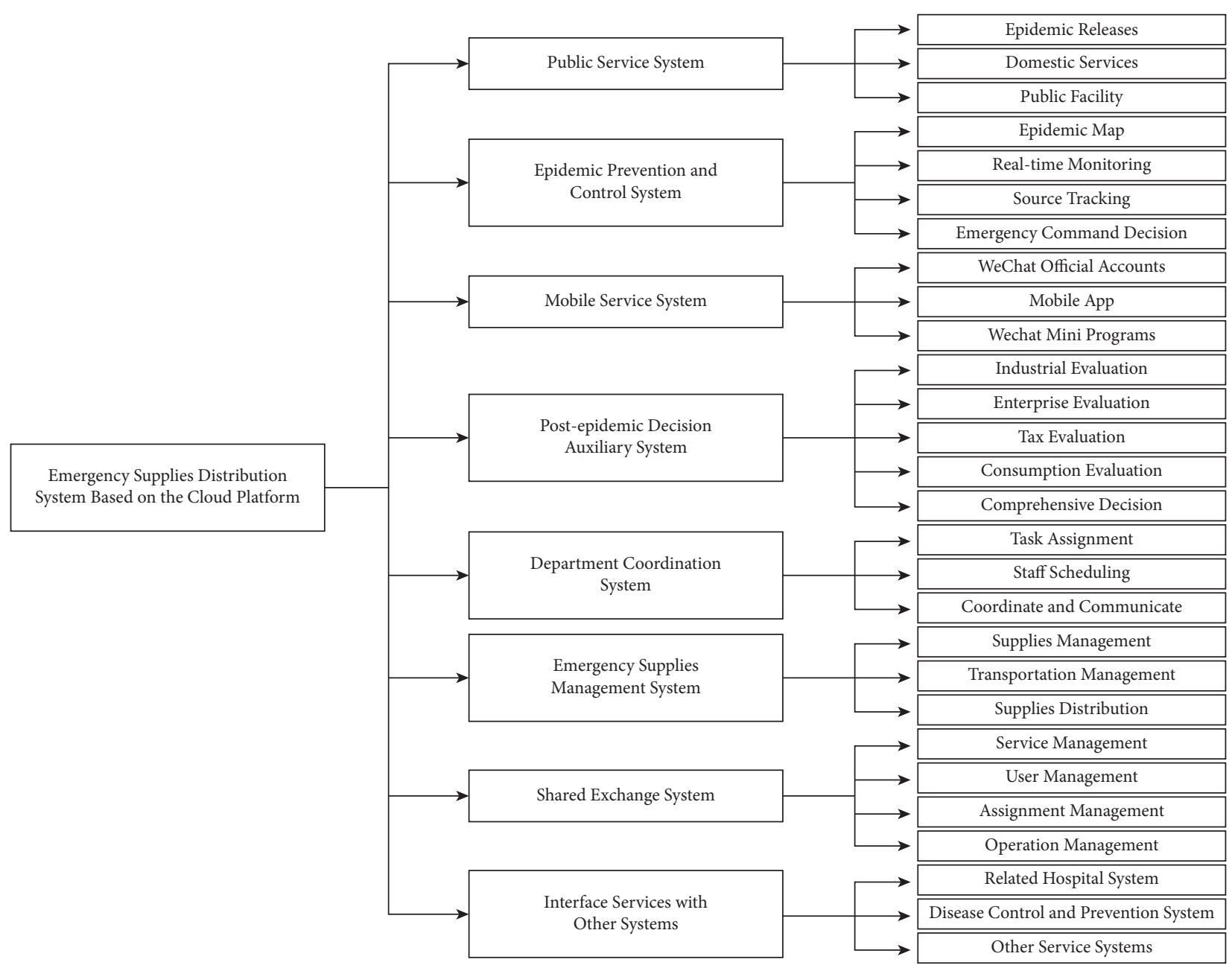

FIGURE 2: The functions of the emergency supplies distribution system based on the cloud platform.

supplies demand of the demand point, which makes it unnecessary for the vehicles to transit through the distribution center as in the traditional model, hence can directly complete the supplies distribution from the supplier to the demand point. To optimize the distribution model, the time, and the cost of the overall emergency logistics network, it is necessary to reasonably plan the distribution route and the position of each node to minimize the sum of the costs and time of all routes. Furthermore, it is necessary to consider route optimization and establish a cloud platform emergency supplies distribution model to achieve optimal supplies distribution.

Concerning the actual scenario of emergency supplies distribution in COVID-19, the following assumptions are made in combination with the characteristics of the cloud platform:

(1) In the process of emergency supplies distribution, a vehicle can only transport one kind of supplies at a time.

(2) The transaction cost does not incur in the distribution of emergency supplies based on the cloud platform.
(3) The cloud platform in this paper is led by the state. Hence, the node does not need to consider the construction cost of the cloud platform.

3.1. Parameter Setting. The relevant parameters and decision variables of the emergency supplies distribution model are presented in Table 1.

3.2. System Model. Based on the aforementioned model, the cost of the emergency supplies distribution model in the epidemic is

$$
\begin{aligned}
\operatorname{Min} C= & H+\sum_{i \in V} \sum_{j \in V} \sum_{n \in N} \sum_{k \in K} C_{l} x_{i j k n} \\
& +\sum_{i \in V} \sum_{j \in V} \sum_{n \in N} \sum_{k \in K} c_{i j k} x_{i j k n}\left(d_{i n}^{2}+d_{j n}^{3}\right), \\
\operatorname{Min} C^{\prime}= & \sum_{i \in V} \sum_{j \in V} \sum_{n \in N} \sum_{k \in K} C_{l} a_{i j k}^{p}+\sum_{i \in V} \sum_{j \in V} \sum_{k \in K} c_{i j k} a_{i j k k}^{p} d_{i j}^{1},
\end{aligned}
$$




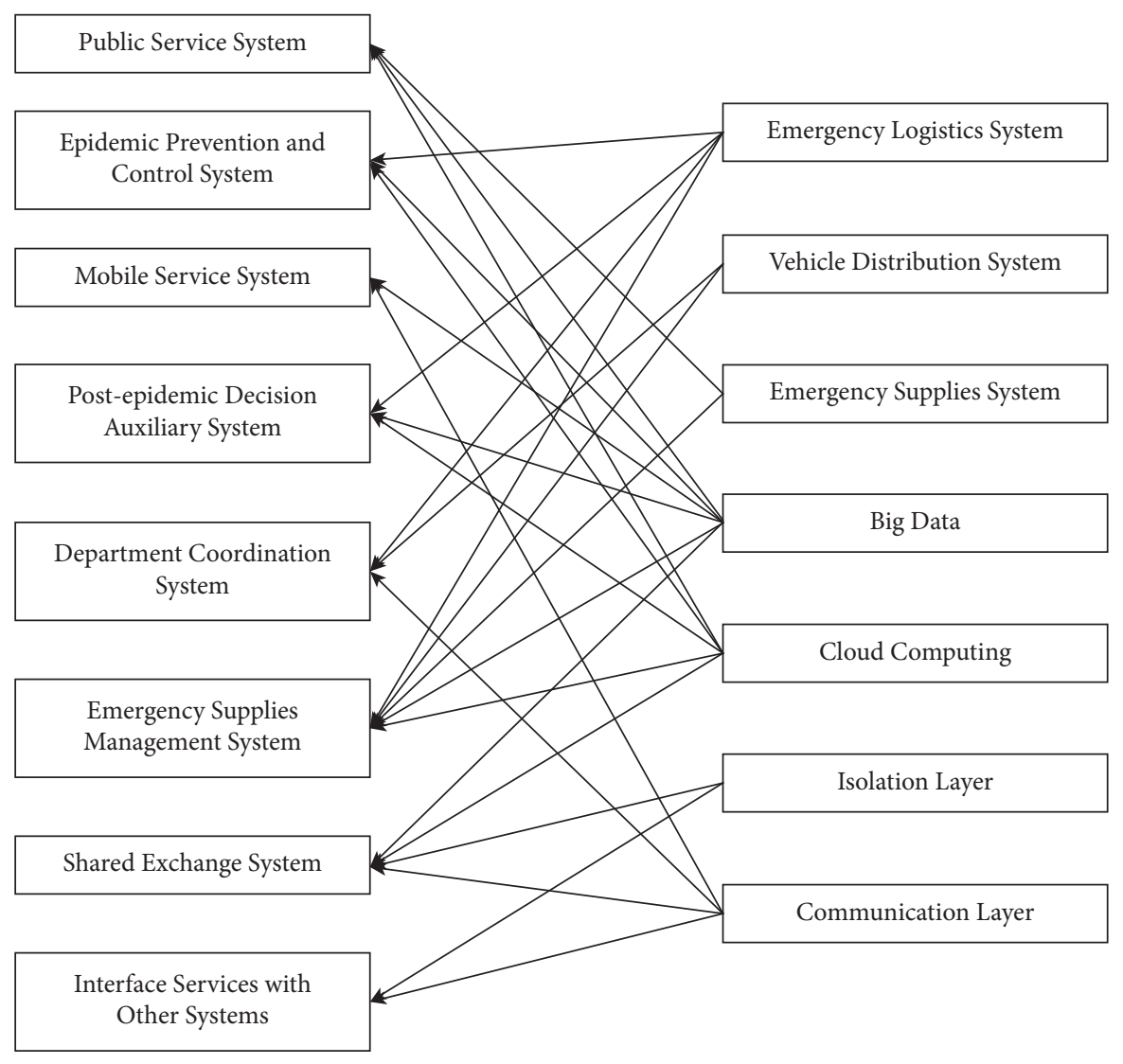

Figure 3: The collaboration model between emergency systems.

$$
\operatorname{Min} T=\sum_{i \in V} \sum_{j \in V} \sum_{n \in N} \sum_{k \in K} T_{l} x_{i j k n}+\sum_{i \in V} \sum_{j \in V} \sum_{n \in N} \sum_{k \in K} x_{i j k n} \frac{d_{i n}^{2}+d_{j n}^{3}}{v}
$$

$\operatorname{MinT}^{\prime}=\sum_{i \in V} \sum_{j \in V} \sum_{n \in N} \sum_{k \in K} T_{l} a_{i j k}^{p}+\sum_{i \in V} \sum_{j \in V} \sum_{k \in K} a_{i j k}^{p} \frac{d_{i j}^{1}}{v}$

The objective function in equation (1) represents the minimum integrated cost of the traditional emergency supplies distribution, including the transaction cost in the distribution of emergency supplies, the loading and unloading cost, and the transportation cost. Equation (2) also represents the minimum integrated cost of emergency supplies distribution based on the cloud platform, including the loading and unloading costs and transportation costs. Equations (3) and (4) are the minimum time in the traditional and cloud platform models, respectively, including the loading and unloading and transportation time. We also have the following constraints:

$$
\begin{gathered}
\sum_{i \in N \cup I} \sum_{n \in N} \sum_{k \in K} x_{i j k n}=a_{i j k}^{p}, \forall j \in J, \forall p \in P, \\
\sum_{i \in N \cup J} \sum_{n \in N} \sum_{k \in K} x_{i j k n}=a_{i j k}^{p}, \forall j \in J, \forall p \in P,
\end{gathered}
$$

$$
\begin{array}{r}
\sum_{i \in N} \sum_{n \in N} \sum_{k \in K} x_{i j k n}=1, \forall j \in J, \forall p \in P, \\
\sum_{j \in N} \sum_{n \in N} \sum_{k \in K} x_{i j k n}=1, \forall i \in I, \forall p \in P, \\
\sum_{i \in N} \sum_{k \in K} a_{i j k}^{p}=1, \forall j \in J, \forall p \in P, \\
\sum_{j \in N} \sum_{k \in K} a_{i j k}^{p}=1, \forall j \in J, \forall p \in P,
\end{array}
$$

where equations (5) and (6) ensure that if the distribution center $n$ is selected to serve the point pair $p$, there must be a vehicle to transport emergency supplies; otherwise, no distribution center is selected. Equations (7) and (8) indicate that the emergency supplies from supplier $i$ to demand point $j$ must be solely transported through the distribution center $n$. Equations (9) and (10) also ensure that only one path can be selected for transportation at a time in the traditional model. We further need to make sure the following:

$$
\sum_{i \in I} D_{i}=\sum_{j \in J} S_{j}
$$

$$
\sum_{p \in P} a_{i j k}^{p} d^{p} \leq q_{i j k n} x_{i j k n}, \forall i \in V, \forall j \in V, \forall k \in K, \forall n \in N
$$




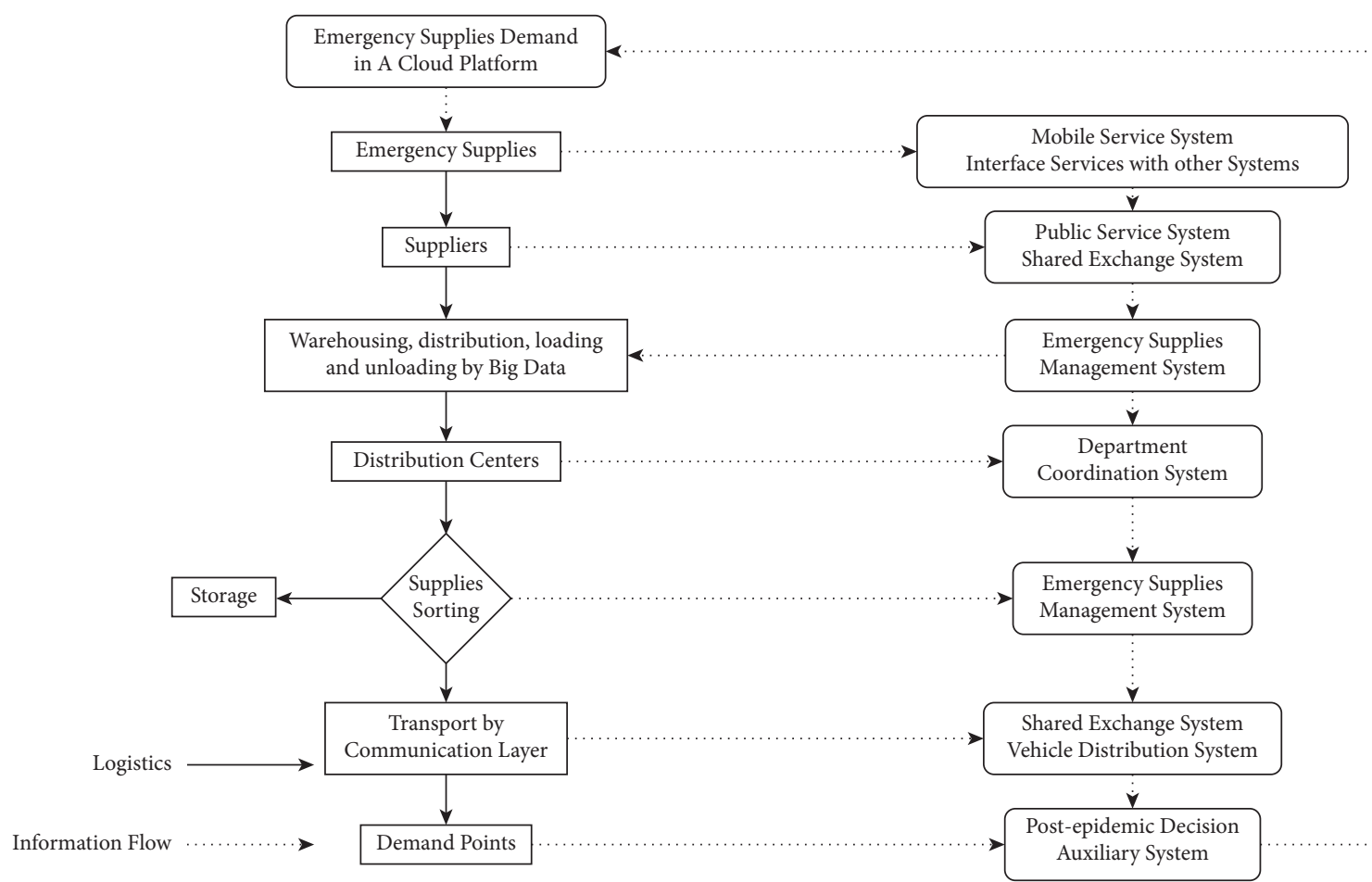

FIGURE 4: The emergency supplies distribution process is based on the proposed cloud platform.

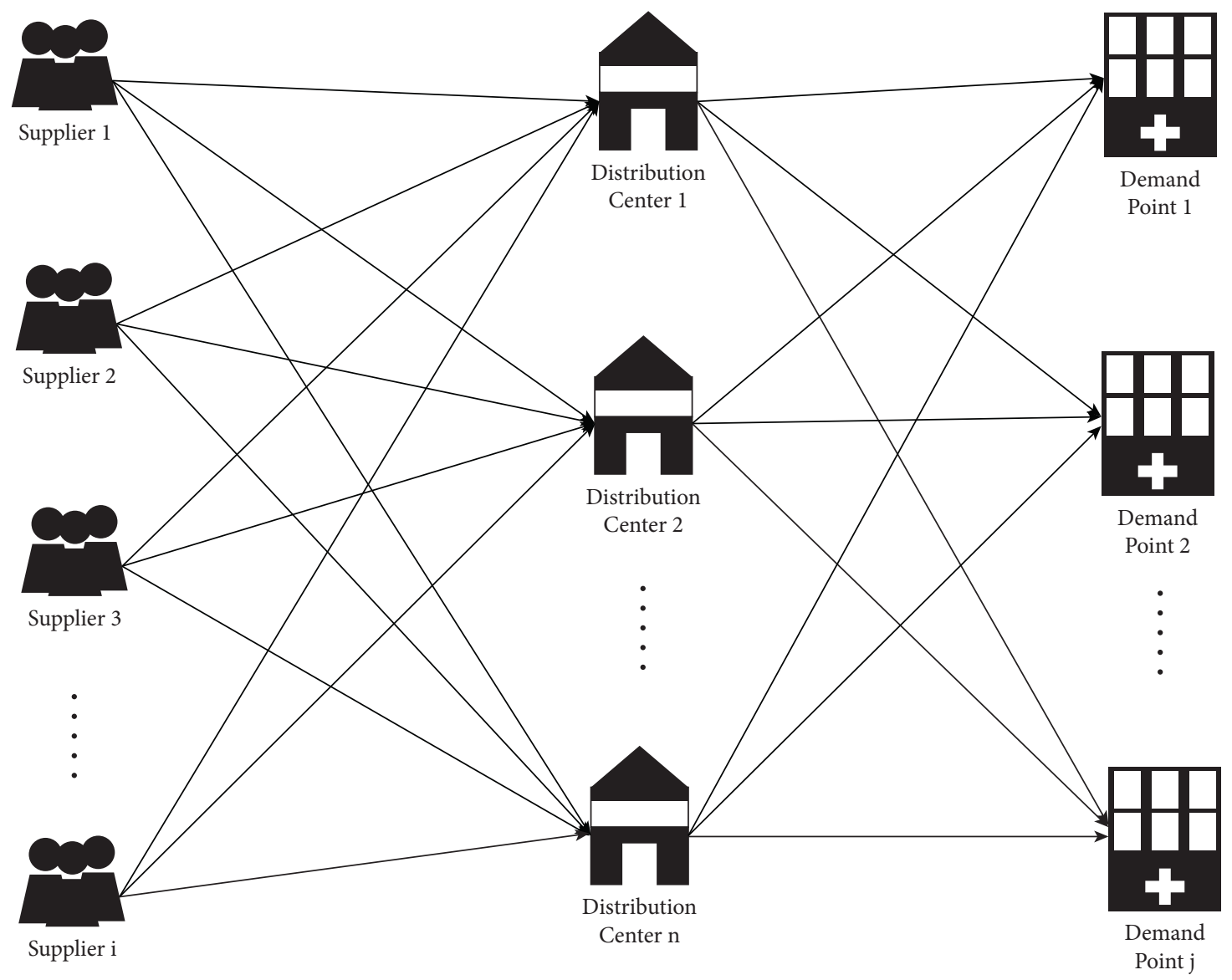

FIgURE 5: The traditional distribution model of emergency supplies in the epidemic. 


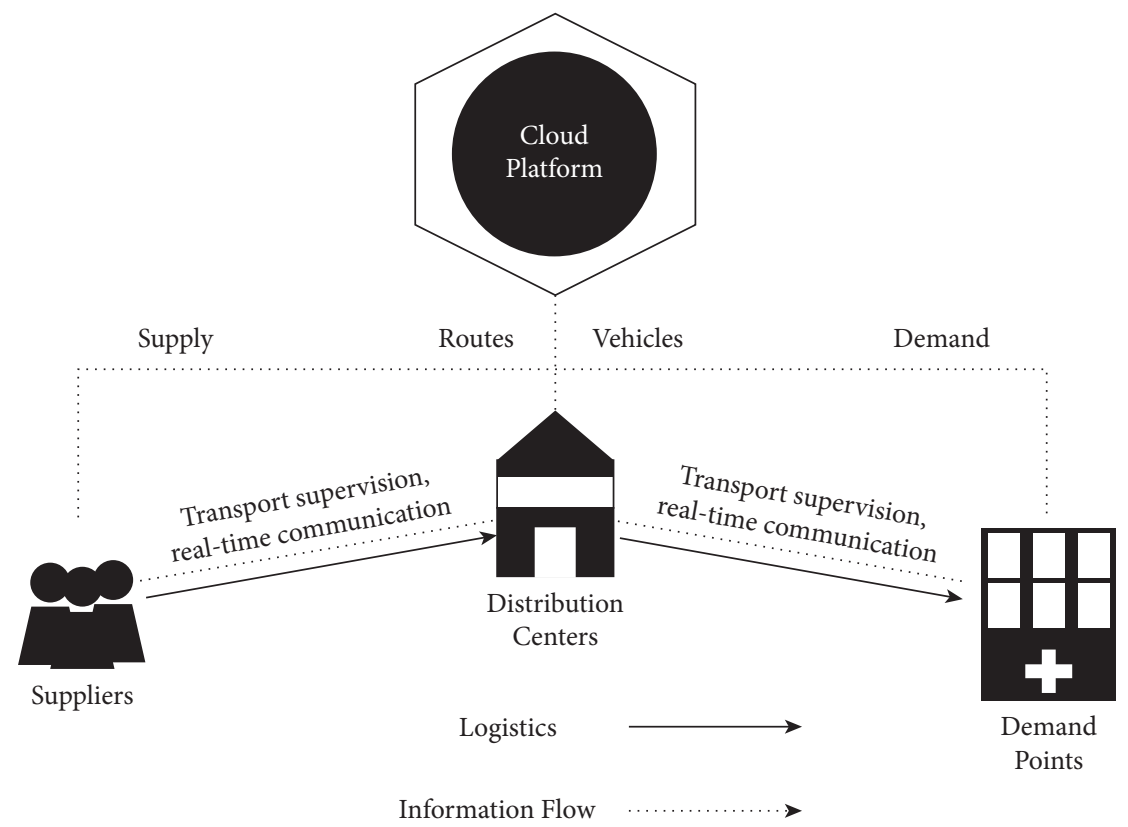

Figure 6: The distribution model of emergency supplies in the epidemic based on the cloud platform.

TABLE 1: Parameters, sets, and decision variables.

\begin{tabular}{|c|c|}
\hline Symbol & Description \\
\hline$\overline{d_{i j}^{1}}$ & The distance from the supplier $i$ to the demand point $j(\mathrm{~km})$ \\
\hline$d_{i n}^{2}$ & The distance from the supplier $i$ to the distribution center $n(\mathrm{~km})$ \\
\hline$d_{j n}^{3}$ & The distance from the demand point $j$ to the distribution center $n(\mathrm{~km})$ \\
\hline$q_{i j k n}$ & $\begin{array}{l}\text { The unit transportation capacity of the vehicle } k \text { from the supplier } i \text { to the demand point } j \text { through the distribution center } n \\
\text { (tons) }\end{array}$ \\
\hline$c_{i j k}$ & The cost of per vehicle per unit distance (yuan $/ \mathrm{km}$ ) \\
\hline$v$ & Vehicle speed $(\mathrm{km} / \mathrm{h})$ \\
\hline$I$ & The set including suppliers indexed by $i, I=\{0,1,2, \ldots, i\}$ \\
\hline$J$ & The set including demand points indexed by $j, J=\{0,1,2, \ldots, j\}$ \\
\hline$P$ & The set including supply and demand point pairs from supplier $i$ to the demand point $j$ \\
\hline$N$ & The set including distribution centers indexed by $n, N=\{0,1,2, \ldots, n\}$ \\
\hline$K$ & The set including the transport vehicles indexed by $k, K=\{1,2, \ldots, k\}$ \\
\hline$G_{n}$ & Maximum load of the distribution center $n$ (tons) \\
\hline$T_{l}$ & The loading and unloading time $(\mathrm{h})$ \\
\hline$C_{l}$ & The loading and unloading cost (yuan) \\
\hline$D_{i}$ & The set including emergency supplies provided by the supplier $i$ \\
\hline$Q_{k}$ & Maximum load of transport vehicles (tons) \\
\hline$S_{j}$ & The set including emergency supplies received by demand point $j$ \\
\hline$C$ & The comprehensive cost of emergency supplies distribution of the cloud platform (yuan) \\
\hline$d^{P}$ & The number of emergency supplies between the point pair $p$ in the period, $p P$ \\
\hline$H$ & The transaction cost between nodes without cloud platform service (yuan) $V=I J N$ \\
\hline$x_{i j k n}\{0,1\}$ & If the vehicle $k$ from the supplier $i$ to the demand point $j$ through the distribution center $n$, then $x_{i j k n}=1$, otherwise $x_{i j k n}=0$ \\
\hline$y\{0,1\}$ & If the cloud platform service is not opened, then $y=1$, otherwise $y=0$ \\
\hline$a_{i j k}^{p}\{0,1\}$ & If the supplier $i$ to the demand point $j$ is transported by the vehicle $k$ and serves the point pair $p$, then $a_{p i j k}=1$, otherwise $a_{p i j k}=0$ \\
\hline
\end{tabular}

$$
\begin{aligned}
& \sum_{p \in P} a_{i j k}^{p} q_{i j k n} \leq W_{n} y, \forall n \in N, \\
& q_{i j k n} \geq 0, \forall i \in V, \forall j \in V, \forall k \in K, \\
& \sum_{j \in J} q_{i j k n} \leq D_{i}, \forall i \in I,
\end{aligned}
$$

$$
\begin{aligned}
\sum_{i \in I} q_{i j k n} \leq S_{j}, \forall j \in J, \\
a_{i j k}^{p} \in\{0,1\}, \forall i \in V, \forall j \in V, \forall k \in K, \forall p \in P, \\
x_{i j k n} \in\{0,1\}, \forall i \in V, \forall j \in V, \forall n \in V, \forall k \in K .
\end{aligned}
$$


In the aforementioned equations, equation (11) ensures that the number of emergency supplies provided by all suppliers is the same as all demand points received it. Equation (12) enforces the transportation capacity constraint, which requires that the distribution center $n$ selected for the transport path between the point pair $p$ must be active. Equation (13) also enforces the transportation capacity of the distribution center $n$. Equations (14) to (16) also apply the transportation capacity constraints between the points, where equations (17) to (18) are the decision variables related to the emergency supplies distribution model.

3.3. Algorithm Design. The distribution of emergency supplies in the epidemic based on cloud platforms extends the traditional logistics transport problem. Furthermore, the emergency supplies distribution model in this paper involves multiple distribution centers and multiple demand points. Therefore, it is necessary to adopt an intelligent optimization algorithm to solve the problem. Here, we propose using the genetic algorithm. The steps of the genetic algorithm in this research are as follows:

Step 1: Population Initialization. Number each demand point, randomly arrange and generate chromosomes, and reserve them in a matrix to form the initial population.

Step 2: Calculate Fitness. Calculate the transport distance of each chromosome in the initial population. Then add the supply requirements of each demand point and the upper limit of the vehicle load into the fitness calculation to find the shortest average time and route. Set the number of iterations $g=1$.

Step 3: Selecting the Chromosome. Select the chromosome with the lowest fitness in this generation as the father's chromosome, and leave the ascending chromosomes as the mother's chromosome.

Step 4: Cross-Variation. Using the monarch scheme, the chromosome with the highest fitness value is selected as the monarch chromosome. It is then placed in the odd-numbered position of the entire population and forms a pair with the even-numbered position of the latter one. The number of crossover points is then determined according to the crossover probability $\left(P_{c}=0.8\right)$, and the population is randomly selected according to the variation probability $P_{m}\left(P_{m}=0.3\right)$ after the cross-operation [41]. The next generation of chromosomes is then generated.

The algorithm calculates the fitness of the population individuals after cross-variation. The minimum fitness of the generation $g$ and the corresponding individual value are recorded. Then it is checked whether the number of iterations exceeds the maximum allowed iterations, $G$. If so, the cycle is stopped, otherwise $g=g+1$, and it returns to Step 4 to re-execute the monarch plan [41-44]. The flowchart of the algorithm is shown in Figure 7.

\section{Experimental and Data Analysis}

To optimize the distribution of emergency supplies, we use MATLAB-generated data using the actual coordinate distribution on the map. We also modify some of the parameters of the sample city for sensitivity analysis and then analyze the stability of the supplies distribution path. In these models, a distribution center $n$, undertakes the transportation task from multiple suppliers $i$ to demand points $j$. When the vehicle is transported in the traditional model, the supplies are loaded once at the supplier, then loaded and unloaded once at the distribution center, and unloaded once at the demand point. The vehicle only needs to load the supplies once at the supplier and unload the supplies at the demand point in the cloud platform model. For brevity, this paper does not consider the fixed opening cost of each point in the emergency logistics network. The points and data in this experiment are based on the Baidu map (https://map.baidu.com/) and the relevant literature [42-45], optimizing the results through MATLAB.

4.1. Emergency Logistics Optimization in the Seriously Affected City Based on the Cloud Platform. The main stations and logistics parks in the seriously affected city are selected as the suppliers. The Red Cross Society and the relevant government departments in the city are selected as the distribution centers. The eight main hospitals in the city are selected as the demand points. The relevant data for each point in the emergency logistics model is presented in Table 2.

Table 3 shows the distance between suppliers, distribution centers, and demand points in the seriously affected city.

This paper assumes that during the opening of each point, the emergency supplies between suppliers and demand points in the seriously affected city are as presented in Table 4.

After the optimization in MATLAB, the integrated cost of the emergency logistics model in the seriously affected city is obtained and shown in Figure 8. The emergency logistics plan is also presented in Table 5. The integrated cost of the emergency logistics in the traditional model is 21,030 yuans, and the integrated time is 17.54; the integrated cost of emergency logistics based on the cloud platform is 14,930 yuans, and the integrated time is 13.51 . It means a reduction of $29.01 \%$ of the cost and $22.98 \%$ of the time using the proposed cloud platform. The distribution path of emergency supplies from suppliers and demand points are also shown in Table 5. For instance, for Demand Point 1, in the traditional emergency logistics model, the supplies it received are provided by Supplier 2 through the 3rd vehicle of Distribution Center 3, Supplier 3 through the 1st vehicle of Distribution Center 1, and also Supplier 4 through the 1st vehicle of distribution Center 3. In the emergency logistics based on the cloud platform, Demand Point 1 can directly receive emergency supplies provided by Suppliers 2, 3, and 4 without transferring through the distribution center. As it is seen, using the proposed cloud platform, emergency supplies 


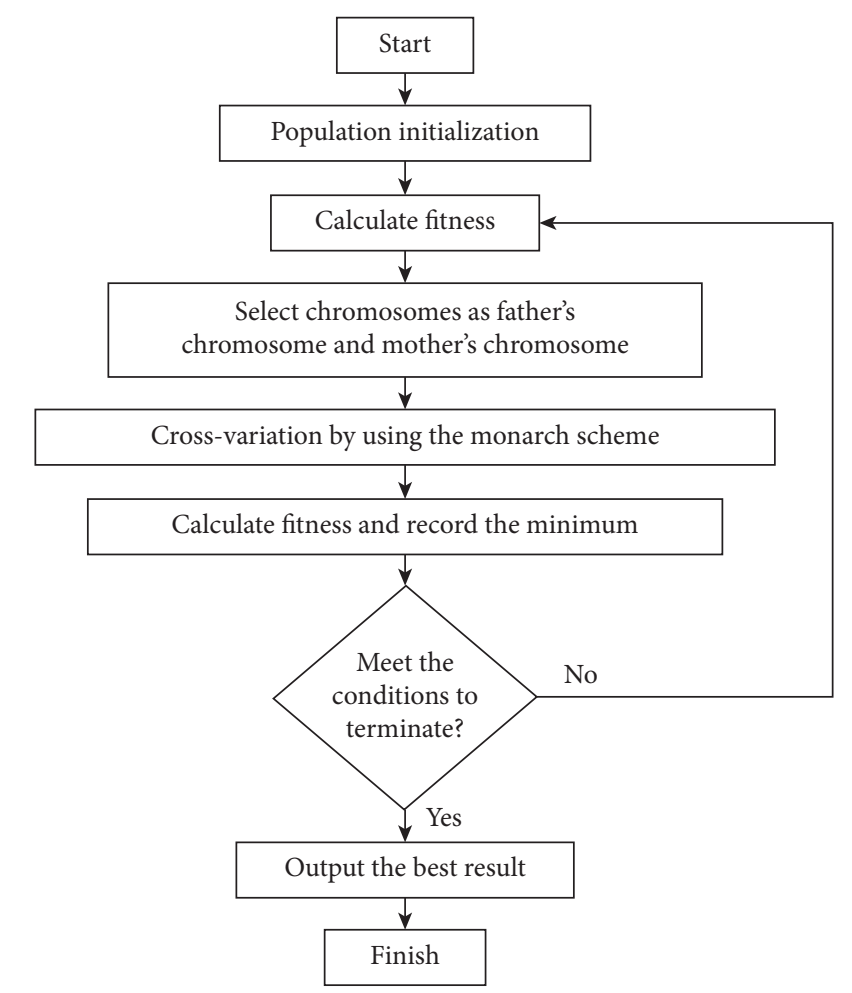

Figure 7: The flowchart of the genetic algorithm for optimization.

can be transported directly from the supplier to the demand point, significantly reducing the transportation process.

\subsection{Emergency Logistics Optimization in the General Affected} City Based on the Cloud Platform. The main stations and logistics parks in the general affected city are selected as the suppliers. The Red Cross Society and the relevant government departments in the city are selected as the distribution centers. The four main hospitals in the city are selected as the demand points. The relevant data for each point in the emergency logistics model is presented in Table 6.

Table 7 shows the distance between suppliers, distribution centers, and demand points in the general affected city.

This paper assumes that during the opening of each point, the emergency supplies between suppliers and demand points in the general affected city are as presented in Table 8.

After the optimization in MATLAB, the integrated cost of the emergency logistics model in the general affected city as shown in Figure 9 and the emergency logistics plan in the general affected city as shown in Table 9. The integrated cost of the emergency logistics in the traditional model is 11,670 yuans, and the integrated time is 10.20; the integrated cost of emergency logistics based on the cloud platform is 9,070 yuans, and the integrated time is 7.49 . It means a reduction of $28.67 \%$ of the cost and $26.59 \%$ of the time using the proposed cloud platform. The distribution path of emergency supplies from suppliers and demand points in the general affected city is shown in Table 9.
4.3. Emergency Logistics Optimization in the Minor Affected City Based on the Cloud Platform. The main stations and logistics parks in the minor affected city are selected as the suppliers. The Red Cross Society and relevant government departments in the city are selected as the distribution centers. The two main hospitals in the city are selected as the demand points. The relevant data for each point in the emergency logistics model is presented in Table 10.

Table 11 shows the distance between suppliers, distribution centers, and demand points in the minor affected city.

This paper assumes that during the opening of each point, the emergency supplies between suppliers and demand points in the minor affected city are as presented in Table 12.

After the optimization in MATLAB, the integrated cost of the emergency logistics model in the minor affected city as shown in Figure 10, and the emergency logistics plan in the minor affected city as shown in Table 13. The integrated cost of the emergency logistics in the traditional model is 4,840 yuans, and the integrated time is 3.15; the integrated cost of emergency logistics based on the cloud platform is 3,740 yuans, and the integrated time is 1.99 . It means a reduction of $22.73 \%$ of the cost and $36.65 \%$ of the time using the proposed cloud platform. The distribution path of emergency supplies from suppliers and demand points in the minor affected city is shown in Table 13 .

The aforementioned cases show that the cloud platform has played a critical role in reducing the cost and time of emergency supplies distribution. With the city's emergency 
TABLE 2: Relevant points and parameters in the seriously affected city.

\begin{tabular}{|c|c|c|c|c|c|}
\hline Parameter & Symbol & Value & Parameter & Symbol & Value \\
\hline Maximum load of transport vehicles & $Q_{k}$ & $100 \mathrm{t}$ & $\begin{array}{c}\text { Number of transport vehicles in the distribution } \\
\text { center }\end{array}$ & $K$ & 3 \\
\hline Vehicle speed & $v$ & 60 & Emergency supplies received by Demand Point 1 & $S_{1}$ & $120 \mathrm{t}$ \\
\hline Maximum load of Distribution Center 1 & $G_{1}$ & $200 \mathrm{t}$ & Emergency supplies received by Demand Point 2 & $S_{2}$ & $160 t$ \\
\hline Maximum load of Distribution Center 2 & $G_{2}$ & $220 \mathrm{t}$ & Emergency supplies received by Demand Point 3 & $S_{3}$ & $155 \mathrm{t}$ \\
\hline Maximum load of Distribution Center 3 & $G_{3}$ & $170 \mathrm{t}$ & Emergency supplies received by Demand Point 4 & $S_{4}$ & $135 \mathrm{t}$ \\
\hline Maximum load of Distribution Center 4 & $G_{4}$ & $150 \mathrm{t}$ & Emergency supplies received by Demand Point 5 & $S_{5}$ & $110 \mathrm{t}$ \\
\hline Maximum load of Distribution Center 5 & $G_{5}$ & $180 \mathrm{t}$ & Emergency supplies received by Demand Point 6 & $S_{6}$ & $95 \mathrm{t}$ \\
\hline $\begin{array}{l}\text { Emergency supplies provided by } \\
\text { Supplier } 1\end{array}$ & $D_{1}$ & $180 \mathrm{t}$ & Emergency supplies received by Demand Point 7 & $S_{7}$ & $140 \mathrm{t}$ \\
\hline $\begin{array}{l}\text { Emergency supplies provided by } \\
\text { Supplier } 2\end{array}$ & $D_{2}$ & $220 \mathrm{t}$ & Emergency supplies received by Demand Point 8 & $S_{8}$ & $120 \mathrm{t}$ \\
\hline $\begin{array}{l}\text { Emergency supplies provided by } \\
\text { Supplier } 3\end{array}$ & $D_{3}$ & $140 \mathrm{t}$ & Emergency supplies provided by Supplier 5 & $D_{5}$ & $150 \mathrm{t}$ \\
\hline $\begin{array}{l}\text { Emergency supplies provided by } \\
\text { Supplier } 4\end{array}$ & $D_{4}$ & $160 \mathrm{t}$ & The loading and unloading time & $\mathrm{Tl}$ & 0.5 \\
\hline The loading and unloading cost & $C_{l}$ & 100 yuan & The transaction cost in traditional model & $H$ & $\begin{array}{c}300 \\
\text { yuan }\end{array}$ \\
\hline
\end{tabular}

TABLE 3: Distance of each point in the seriously affected city.

\begin{tabular}{|c|c|c|c|c|c|}
\hline & Distribution Center 1 & Distribution Center 2 & Distribution Center 3 & Distribution Center 4 & Distribution Center 5 \\
\hline Supplier 1 & 12.3 & 17.1 & 13.5 & 16.2 & 15.1 \\
\hline Supplier 2 & 6.5 & 15.3 & 4.7 & 14.2 & 6.8 \\
\hline Supplier 3 & 16.5 & 7.7 & 17.5 & 6.4 & 15.4 \\
\hline Supplier 4 & 36.6 & 53.9 & 63.6 & 51.4 & 40.2 \\
\hline Supplier 5 & 25.3 & 37.1 & 44.7 & 39.3 & 30.2 \\
\hline Demand Point 1 & 34.3 & 33.2 & 32.8 & 28.5 & 32.2 \\
\hline Demand Point 2 & 18.7 & 29.3 & 18.8 & 29.8 & 19.6 \\
\hline Demand Point 3 & 15.5 & 5.8 & 16.7 & 4.5 & 15.2 \\
\hline Demand Point 4 & 13.9 & 7.1 & 12.3 & 5.5 & 11.3 \\
\hline Demand Point 5 & 6.3 & 15.2 & 4.3 & 13.9 & 7.8 \\
\hline Demand Point 6 & 3.9 & 14.4 & 3.3 & 13.3 & 6.3 \\
\hline Demand Point 7 & 5.6 & 18.4 & 5 & 15.6 & 5.7 \\
\hline Demand Point 8 & 4.4 & 16.9 & 3.9 & 15.5 & 5.2 \\
\hline
\end{tabular}

TABLE 4: Emergency supplies between suppliers and demand points in the seriously affected city.

\begin{tabular}{|c|c|c|c|c|c|}
\hline & Supplier 1 & Supplier 2 & Supplier 3 & Supplier 4 & Supplier 5 \\
\hline Demand Point 1 & 0 & 80 & 100 & 70 & 0 \\
\hline Demand Point 2 & 80 & 50 & 0 & 0 & 30 \\
\hline Demand Point 3 & 70 & 0 & 70 & 0 & 40 \\
\hline Demand Point 4 & 0 & 40 & 60 & 30 & 0 \\
\hline Demand Point 5 & 60 & 50 & 0 & 40 & 20 \\
\hline Demand Point 6 & 0 & 30 & 50 & 30 & 30 \\
\hline Demand Point 7 & 90 & 0 & 60 & 20 & 0 \\
\hline Demand Point 8 & 60 & 60 & 0 & 70 & 0 \\
\hline
\end{tabular}

levels, the cloud platform has a bigger effect on cost optimization.

4.4. Sensitivity Analysis. Different levels of urban emergency logistics have different integrated cost and distribution paths due to different factors, such as supplies demand and transportation capacity constraints. With the level of emergency increased, the demand for emergency supplies and the cost of transportation increased. It is seen that the unit transportation cost $c_{i j k n}$ and the loading and unloading cost $C_{l}$ have significant impacts on the supplies distribution. To further verify the impact of these factors on the emergency logistics based on the cloud platform, this paper 


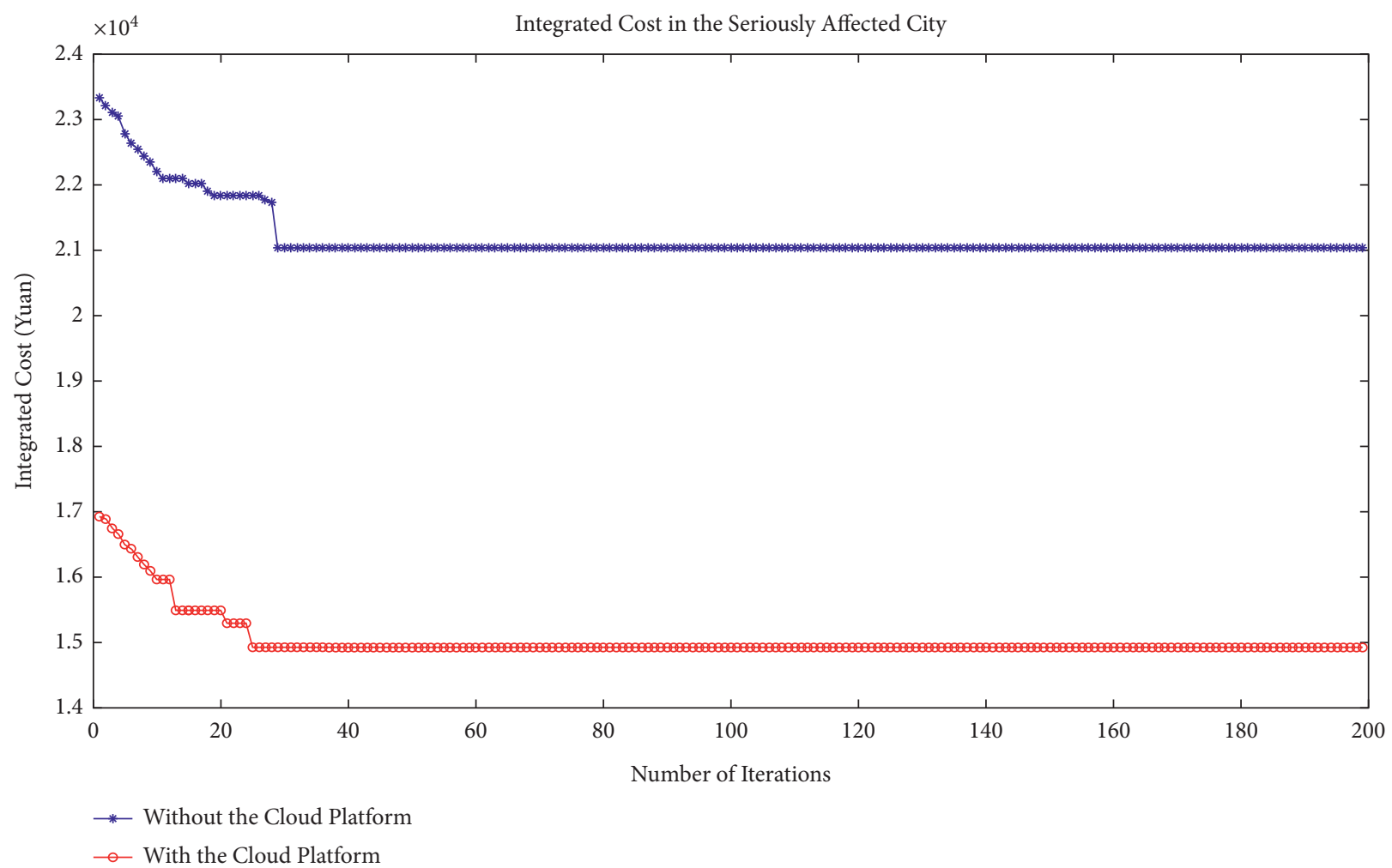

FIGURE 8: Integrated costs in the seriously affected city.

TABle 5: The distribution path of emergency supplies in the seriously affected city.

\begin{tabular}{|c|c|c|c|c|c|}
\hline \multicolumn{3}{|c|}{ Without the cloud platform } & \multicolumn{3}{|c|}{ With the cloud platform } \\
\hline Supplier & Demand Point & Distribution path & Supplier & Demand Point & Distribution path \\
\hline 2 & 1 & $2 \longrightarrow 3 \longrightarrow 1(1)$ & 2 & 1 & $2 \longrightarrow 1$ \\
\hline 3 & 1 & $3 \longrightarrow 1 \longrightarrow 1(3)$ & 3 & 1 & $3 \longrightarrow 1$ \\
\hline 4 & 1 & $4 \longrightarrow 3 \longrightarrow 1(1)$ & 4 & 1 & $4 \longrightarrow 1$ \\
\hline 1 & 2 & $1 \longrightarrow 4 \longrightarrow 2(3)$ & 1 & 2 & $1 \longrightarrow 2$ \\
\hline 2 & 2 & $2 \longrightarrow 3 \longrightarrow 2(1)$ & 2 & 2 & $2 \longrightarrow 2$ \\
\hline 5 & 2 & $5 \longrightarrow 4 \longrightarrow 2(1)$ & 5 & 2 & $5 \longrightarrow 2$ \\
\hline 1 & 3 & $1 \longrightarrow 4 \longrightarrow 3(1)$ & 1 & 3 & $1 \longrightarrow 3$ \\
\hline 3 & 3 & $3 \longrightarrow 4 \longrightarrow 3(2)$ & 3 & 3 & $3 \longrightarrow 3$ \\
\hline 5 & 3 & $5 \longrightarrow 1 \longrightarrow 3(2)$ & 5 & 3 & $5 \longrightarrow 3$ \\
\hline 2 & 4 & $2 \longrightarrow 1 \longrightarrow 4(3)$ & 2 & 4 & $2 \longrightarrow 4$ \\
\hline 3 & 4 & $3 \longrightarrow 4 \longrightarrow 4(3)$ & 3 & 4 & $3 \longrightarrow 4$ \\
\hline 4 & 4 & $4 \longrightarrow 5 \longrightarrow 4(2)$ & 4 & 4 & $4 \longrightarrow 4$ \\
\hline 1 & 5 & $1 \longrightarrow 4 \longrightarrow 5(3)$ & 1 & 5 & $1 \longrightarrow 5$ \\
\hline 2 & 5 & $2 \longrightarrow 5 \longrightarrow 5(2)$ & 2 & 5 & $2 \longrightarrow 5$ \\
\hline 4 & 5 & $4 \longrightarrow 3 \longrightarrow 5(2)$ & 4 & 5 & $4 \longrightarrow 5$ \\
\hline 5 & 5 & $5 \longrightarrow 5 \longrightarrow 5(2)$ & 5 & 5 & $5 \longrightarrow 5$ \\
\hline 2 & 6 & $2 \longrightarrow 3 \longrightarrow 6(3)$ & 2 & 6 & $2 \longrightarrow 6$ \\
\hline 3 & 6 & $3 \longrightarrow 3 \longrightarrow 6(2)$ & 3 & 6 & $3 \longrightarrow 6$ \\
\hline 4 & 6 & $4 \longrightarrow 1 \longrightarrow 6(2)$ & 4 & 6 & $4 \longrightarrow 6$ \\
\hline 5 & 6 & $5 \longrightarrow 1 \longrightarrow 6(3)$ & 5 & 6 & $5 \longrightarrow 6$ \\
\hline 1 & 7 & $1 \longrightarrow 1 \longrightarrow 7(3)$ & 1 & 7 & $1 \longrightarrow 7$ \\
\hline 3 & 7 & $3 \longrightarrow 3 \longrightarrow 7(3)$ & 3 & 7 & $3 \longrightarrow 7$ \\
\hline 4 & 7 & $4 \longrightarrow 3 \longrightarrow 7(2)$ & 4 & 7 & $4 \longrightarrow 7$ \\
\hline 1 & 8 & $1 \longrightarrow 3 \longrightarrow 8(1)$ & 1 & 8 & $1 \longrightarrow 8$ \\
\hline 2 & 8 & $2 \longrightarrow 2 \longrightarrow 8(3)$ & 2 & 8 & $2 \longrightarrow 8$ \\
\hline 4 & 8 & $4 \longrightarrow 5 \longrightarrow 8(2)$ & 4 & 8 & $4 \longrightarrow 8$ \\
\hline
\end{tabular}


TABLE 6: Relevant points and parameters in the general affected city.

\begin{tabular}{|c|c|c|c|c|c|}
\hline Parameter & Symbol & Value & Parameter & Symbol & Value \\
\hline Maximum load of transport vehicles & $Q_{k}$ & $100 \mathrm{t}$ & $\begin{array}{c}\text { Number of transport vehicles in the distribution } \\
\text { center }\end{array}$ & $K$ & 3 \\
\hline Maximum load of Distribution Center 1 & $G_{1}$ & $170 \mathrm{t}$ & Vehicle speed & $v$ & 60 \\
\hline Maximum load of Distribution Center 2 & $G_{2}$ & $150 \mathrm{t}$ & Emergency supplies received by Demand Point 1 & $S_{1}$ & $120 t$ \\
\hline Maximum load of Distribution Center 3 & $G_{3}$ & $180 \mathrm{t}$ & Emergency supplies received by Demand Point 2 & $S_{2}$ & $110 \mathrm{t}$ \\
\hline $\begin{array}{l}\text { Emergency supplies provided by } \\
\text { Supplier } 1\end{array}$ & $D_{1}$ & $110 \mathrm{t}$ & Emergency supplies received by Demand Point 3 & $S_{3}$ & $100 t$ \\
\hline $\begin{array}{l}\text { Emergency supplies provided by } \\
\text { Supplier } 2\end{array}$ & $D_{2}$ & $130 \mathrm{t}$ & Emergency supplies received by Demand Point 4 & $S_{4}$ & $130 \mathrm{t}$ \\
\hline $\begin{array}{l}\text { Emergency supplies provided by } \\
\text { Supplier } 3\end{array}$ & $D_{3}$ & $90 \mathrm{t}$ & The loading and unloading cost & $C_{l}$ & $\begin{array}{c}100 \\
\text { yuan }\end{array}$ \\
\hline $\begin{array}{l}\text { Emergency supplies provided by } \\
\text { Supplier } 4\end{array}$ & $D_{4}$ & $100 t$ & The loading and unloading time & $\mathrm{Tl}$ & 0.5 \\
\hline The cost of per vehicle per unit distance & $c_{i j k n}$ & $\begin{array}{l}7 \text { yuan/ } \\
\mathrm{t} * \mathrm{~km}\end{array}$ & The transaction cost in traditional model & $H$ & $\begin{array}{c}300 \\
\text { yuan }\end{array}$ \\
\hline
\end{tabular}

TABLE 7: Distance of each point in the general affected city.

\begin{tabular}{lccc}
\hline & Distribution Center 1 & Distribution Center 2 & Distribution Center 3 \\
\hline Supplier 1 & 44.8 & 15.2 & 14.7 \\
Supplier 2 & 35.5 & 5.1 & 5.5 \\
Supplier 3 & 90.3 & 65.2 & 50.3 \\
Supplier 4 & 38.9 & 22.2 & 19.9 \\
Demand Point 1 & 48.6 & 8.4 & 9.5 \\
Demand Point 2 & 36 & 9.1 & 8.8 \\
Demand Point 3 & 33.3 & 9.6 & 7.7 \\
Demand Point 4 & 44.4 & 8.2 & 7.3 \\
\hline
\end{tabular}

TABLE 8: Emergency supplies between suppliers and demand points in the general affected city.

\begin{tabular}{lcccc}
\hline & Supplier 1 & Supplier 2 & Supplier 3 & Supplier 4 \\
\hline Demand Point 1 & 0 & 100 & 0 & 80 \\
Demand Point 2 & 90 & 0 & 120 & 130 \\
Demand Point 3 & 130 & 100 & 80 & 0 \\
Demand Point 4 & 0 & 0 & 110 & 70 \\
\hline
\end{tabular}

changes the value of $c_{i j k n}$ and $C_{l}$, keeping the other parameters unchanged. We then explore the impact of these parameters on the integrated cost to investigate the stability of emergency logistics. The final results are presented in Table 14.

The sensitivity analysis of different parameters in Table 6 suggests the following:

(1) Given a limited amount of time, with the intensification of emergency levels (or increasing the number of demand points), the impact of the unit transportation cost of the emergency logistics is decreased. In contrast, the impact of the loading and unloading cost of emergency logistics is increased.

(2) The cloud platform can play a good role in optimizing the integrated cost of emergency logistics; the effect increases with the increasing emergency levels.

(3) Although the integrated cost of the emergency logistics fluctuates by the changes in parameters, the distribution path and the integrated time have not changed. This confirms that the distribution model is stable and can optimize the distribution path of the emergency supplies. 


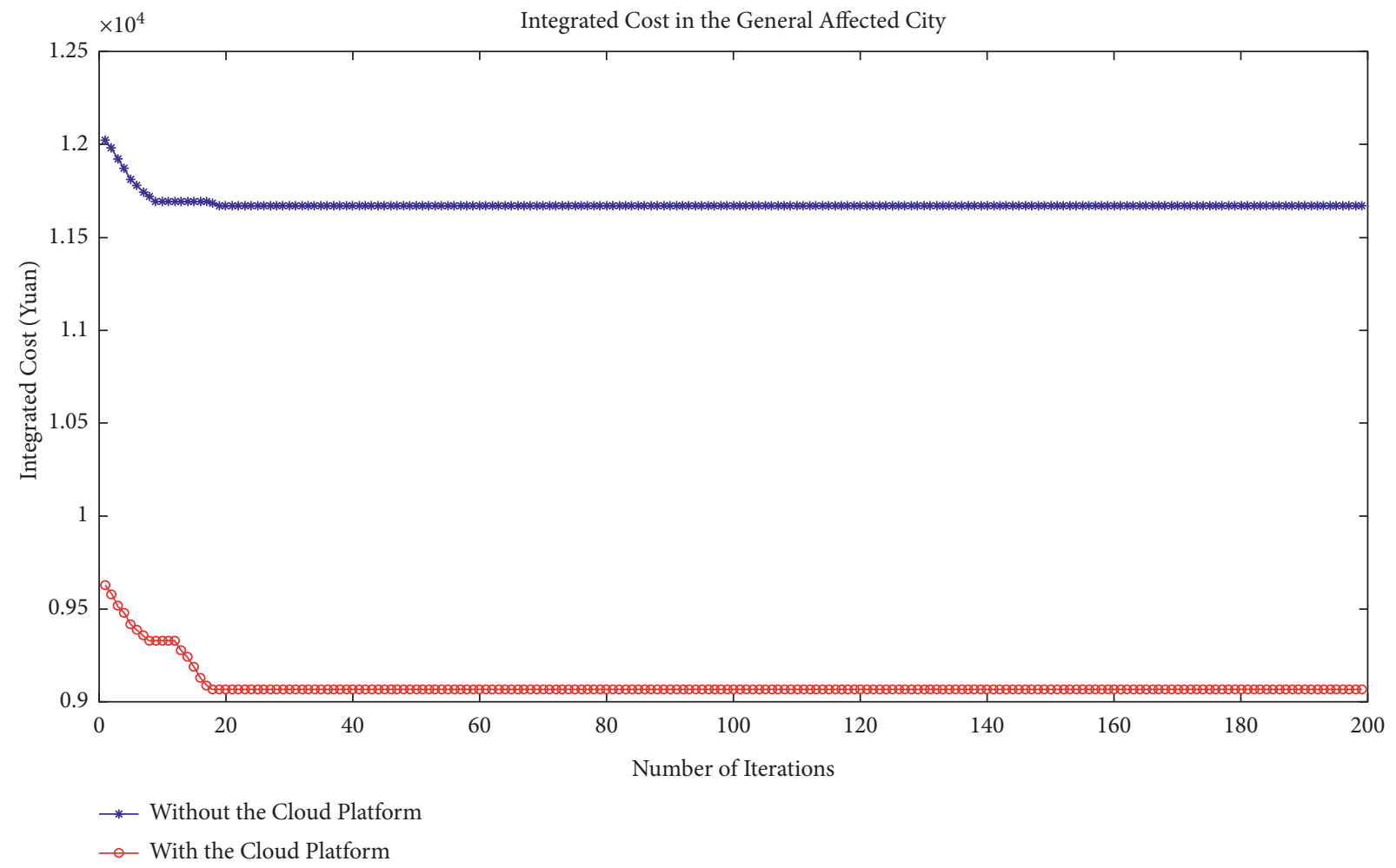

FIGURE 9: Integrated cost in the general affected city.

TABLE 9: The distribution path of emergency supplies in the general affected city.

\begin{tabular}{|c|c|c|c|c|c|}
\hline \multicolumn{3}{|c|}{ Without the cloud platform } & \multicolumn{3}{|c|}{ With the cloud platform } \\
\hline Supplier & Demand point & Distribution path & Supplier & Demand point & Distribution path \\
\hline 2 & 1 & $2 \longrightarrow 1 \longrightarrow 1(3)$ & 2 & 1 & $2 \longrightarrow 1$ \\
\hline 4 & 1 & $4 \longrightarrow 3 \longrightarrow 1(3)$ & 4 & 1 & $4 \longrightarrow 1$ \\
\hline 1 & 2 & $1 \longrightarrow 2 \longrightarrow 2(1)$ & 1 & 2 & $1 \longrightarrow 2$ \\
\hline 3 & 2 & $3 \longrightarrow 2 \longrightarrow 2(2)$ & 3 & 2 & $3 \longrightarrow 2$ \\
\hline 4 & 2 & $4 \longrightarrow 3 \longrightarrow 2(3)$ & 4 & 2 & $4 \longrightarrow 2$ \\
\hline 1 & 3 & $1 \longrightarrow 3 \longrightarrow 3(3)$ & 1 & 3 & $1 \longrightarrow 3$ \\
\hline 2 & 3 & $2 \longrightarrow 3 \longrightarrow 3(1)$ & 2 & 3 & $2 \longrightarrow 3$ \\
\hline 3 & 3 & $3 \longrightarrow 2 \longrightarrow 3$ & 3 & 3 & $3 \longrightarrow 3$ \\
\hline 3 & 4 & $3 \longrightarrow 3 \longrightarrow 4(2)$ & 3 & 4 & $4 \longrightarrow 4$ \\
\hline 4 & 4 & $4 \longrightarrow 1 \longrightarrow 4(1)$ & 4 & 4 & $4 \longrightarrow 4$ \\
\hline
\end{tabular}

TABLE 10: Relevant points and parameters in the minor affected city.

\begin{tabular}{|c|c|c|c|c|c|}
\hline Parameter & Symbol & Value & Parameter & Symbol & Value \\
\hline Maximum load of transport vehicles & $Q_{k}$ & $100 \mathrm{t}$ & $\begin{array}{c}\text { Number of transport vehicles in the distribution } \\
\text { center }\end{array}$ & $K$ & 3 \\
\hline Maximum load of Distribution Center 1 & $G_{1}$ & $100 \mathrm{t}$ & Vehicle speed & $v$ & 60 \\
\hline Maximum load of Distribution Center 2 & $G_{2}$ & $100 \mathrm{t}$ & Emergency supplies received by Demand Point 1 & $S_{1}$ & $90 \mathrm{t}$ \\
\hline $\begin{array}{l}\text { Emergency supplies provided by } \\
\text { Supplier } 1\end{array}$ & $D_{1}$ & $70 \mathrm{t}$ & Emergency supplies received by Demand Point 2 & $S_{2}$ & $110 \mathrm{t}$ \\
\hline $\begin{array}{l}\text { Emergency supplies provided by } \\
\text { Supplier } 2\end{array}$ & $D_{2}$ & $70 t$ & Emergency supplies provided by Supplier 3 & $D_{3}$ & $60 \mathrm{t}$ \\
\hline The loading and unloading cost & $\mathrm{Cl}$ & 100 yuan & The loading and unloading time & $T l$ & 0.5 \\
\hline The cost of per vehicle per unit distance & $c_{i j k n}$ & 7 yuan $/ \mathrm{t} * \mathrm{~km}$ & The transaction cost in traditional model & $H$ & $\begin{array}{c}300 \\
\text { yuan }\end{array}$ \\
\hline
\end{tabular}


TABLE 11: Distance of each point in the minor affected city.

\begin{tabular}{lcc}
\hline & Distribution Center 1 & Distribution Center 2 \\
\hline Supplier 1 & 11.1 & 8.2 \\
Supplier 2 & 23.2 & 27.1 \\
Supplier 3 & 9.3 & 12.3 \\
Demand Point 1 & 2.8 & 2.8 \\
Demand Point 2 & 1.9 & 3.7 \\
\hline
\end{tabular}

TABLE 12: Emergency supplies between suppliers and demand points in the minor affected city.

\begin{tabular}{lccc}
\hline & Supplier 1 & Supplier 2 & Supplier 3 \\
\hline Demand Point 1 & 100 & 0 & 120 \\
Demand Point 2 & 90 & 110 & 0 \\
\hline
\end{tabular}

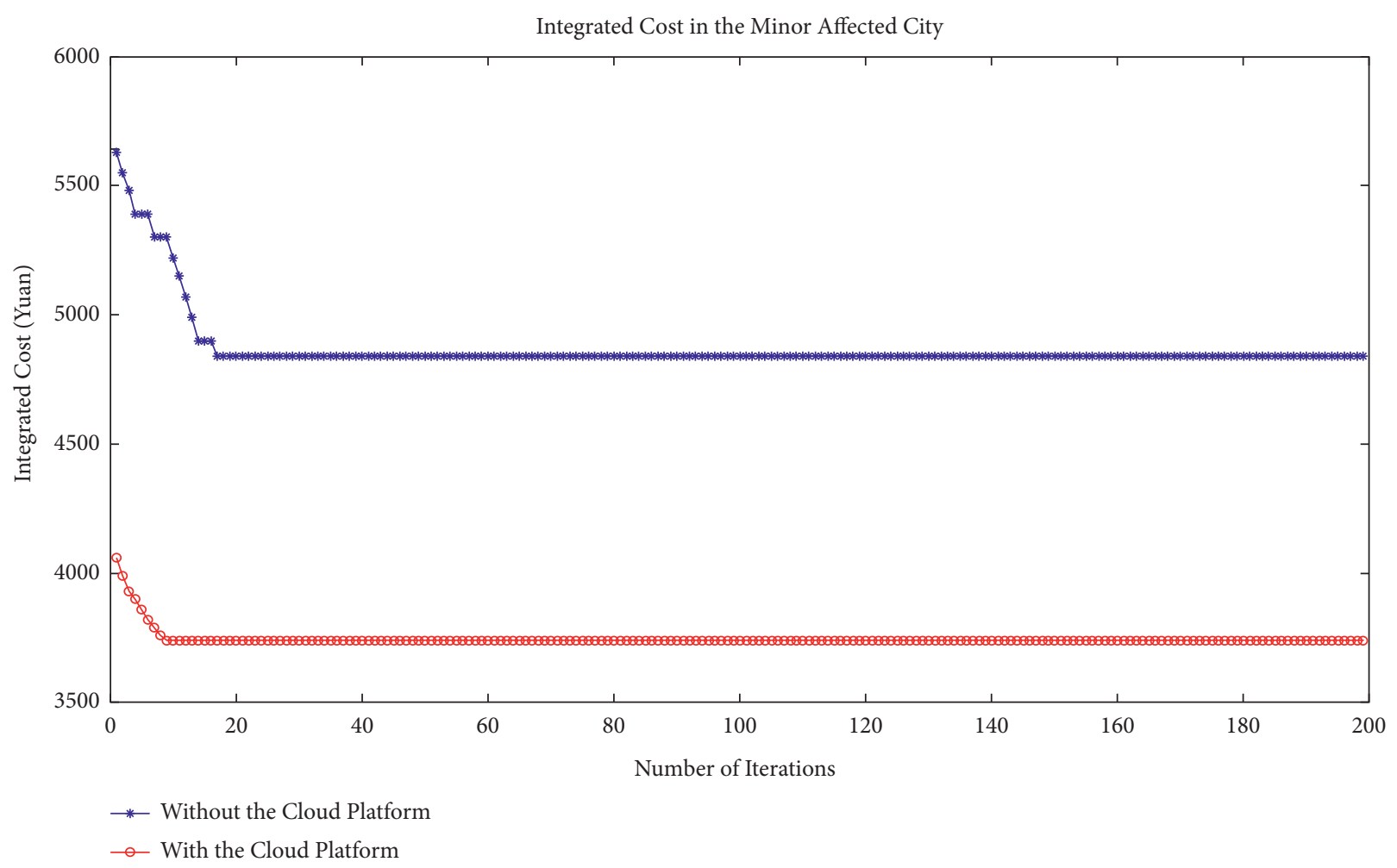

FIGURE 10: Integrated cost in the minor affected city.

TABLE 13: The distribution path of emergency supplies in the minor affected city.

\begin{tabular}{|c|c|c|c|c|c|}
\hline \multicolumn{3}{|c|}{ Without the cloud platform } & \multicolumn{3}{|c|}{ With the cloud platform } \\
\hline Supplier & Demand point & Distribution path & Supplier & Demand point & Distribution path \\
\hline 1 & 1 & $1 \longrightarrow 1 \longrightarrow 1(4)$ & 1 & 1 & $1 \longrightarrow 1$ \\
\hline 3 & 1 & $3 \longrightarrow 1 \longrightarrow 1(1)$ & 2 & 1 & $2 \longrightarrow 1$ \\
\hline 1 & 2 & $1 \longrightarrow 1 \longrightarrow 2(2)$ & 2 & 2 & $2 \longrightarrow 2$ \\
\hline 2 & 2 & $2 \longrightarrow 2 \longrightarrow 2(2)$ & 3 & 2 & $3 \longrightarrow 2$ \\
\hline
\end{tabular}


TABLE 14: Sensitivity analysis of emergency logistics supplies distribution.

\begin{tabular}{|c|c|c|c|c|c|c|c|c|}
\hline & \multirow[b]{2}{*}{ Symbol } & \multirow[b]{2}{*}{ Value } & \multicolumn{2}{|c|}{ Seriously affected city } & \multicolumn{2}{|c|}{ General affected city } & \multicolumn{2}{|c|}{ Minor affected city } \\
\hline & & & $\begin{array}{c}\text { Cost } \\
\text { (yuan) }\end{array}$ & $\begin{array}{c}\text { Degree of } \\
\text { change }\end{array}$ & $\begin{array}{c}\text { Cost } \\
\text { (yuan) }\end{array}$ & $\begin{array}{c}\text { Degree of } \\
\text { change }\end{array}$ & $\begin{array}{c}\text { Cost } \\
\text { (yuan) }\end{array}$ & $\begin{array}{c}\text { Degree of } \\
\text { change }\end{array}$ \\
\hline \multirow{6}{*}{ Without the cloud platform } & \multirow{4}{*}{$c_{i j k n}$} & 3.5 & 16,165 & $-23.13 \%$ & 8135 & $-30.29 \%$ & 3370 & $-30.37 \%$ \\
\hline & & 7 & 21,030 & - & 11,670 & - & 4840 & - \\
\hline & & 14 & 30,760 & $+46.27 \%$ & 18,740 & $+60.58 \%$ & 7780 & $+60.74 \%$ \\
\hline & & 50 & 15,830 & $-24.73 \%$ & 9670 & $-17.14 \%$ & 4040 & $-16.53 \%$ \\
\hline & \multirow[t]{2}{*}{$C_{l}$} & 100 & 21,030 & - & 11,670 & - & 4840 & - \\
\hline & & 200 & 31,430 & $+49.45 \%$ & 15,670 & $+34.28 \%$ & 6440 & $+33.06 \%$ \\
\hline \multirow{6}{*}{ With the cloud platform } & \multirow{3}{*}{$c_{i j k n}$} & 3.5 & 10,065 & $-32.59 \%$ & 5535 & $-38.97 \%$ & 2270 & $-39.30 \%$ \\
\hline & & 7 & 14,930 & - & 9070 & - & 3740 & - \\
\hline & & 14 & 24,660 & $+65.17 \%$ & 16,140 & $+77.95 \%$ & 6680 & $+78.61 \%$ \\
\hline & \multirow{3}{*}{$C_{l}$} & 50 & 12,330 & $-17.41 \%$ & 8070 & $-11.03 \%$ & 3340 & $-10.70 \%$ \\
\hline & & 100 & 14,930 & - & 9070 & - & 3740 & - \\
\hline & & 200 & 20,130 & $+34.83 \%$ & 11,070 & $+22.05 \%$ & 4540 & $+21.39 \%$ \\
\hline
\end{tabular}

\section{Conclusion and Future Works}

The logistics industry plays a vital role in the distribution of emergency supplies. In this paper, we devised a cloud platform for emergency supplies distribution. By establishing an urban emergency supplies distribution path optimization model, our proposed platform optimizes the supplies distribution routes in the epidemic and reduces emergency logistics costs and time.

Although this research has optimized the distribution mode and costs of emergency supplies based on cloud platforms in the epidemic, the results of this research can be extended in the following directions:

(1) Further investigation of multiobjective optimization to achieve the optimal cost and the shortest time for the emergency supplies distribution based on the cloud platform.

(2) Considering the situation of reverse logistics in emergency logistics and optimizing the emergency supplies distribution model from a general perspective.

(3) Considering cross-regional/countries distribution of emergency supplies based on a cloud platform.

(4) At present, there are not many academic studies on the accuracy of cloud platforms supplies distribution [46-48]. In the future, new experimental results will be combined to prove the accuracy and effectiveness of the cloud platform.

\section{Data Availability}

The data that support the findings of this study are available from the correspondence author (wang112111@163.com) upon reasonable request.

\section{Conflicts of Interest}

The authors declare that there are no conflicts of interest.

\section{Acknowledgments}

The authors would like to express their gratitude to EditSprings (https://www.editsprings.com/) for the expert linguistic services. A high tribute shall be paid to Ms Zhang Pei and Ms Zhang Qinghong, whose profound knowledge triggers their effort for revising this paper. This research was funded by Hebei Provincial Department of Education (grant no. SR 201913) and supported by the Development Fund of Innovative Research Team in Shijiazhuang Tiedao University (grant no. 20210993).

\section{References}

[1] Y. He and N. Liu, "Methodology of emergency medical logistics for public health emergencies," Transportation Research Part E: Logistics and Transportation Review, vol. 79, pp. 178-200, 2015.

[2] L. Zhu, "System dynamics analysis of cross-regional coordinative emergency suppliess allocation under sever epidemics," Systems Engineering, vol. 35, no. 6, pp. 105-112, 2017.

[3] C. Liu and G. Kou, "Location-routing problem of emergency logistics system in post-earthquake," Systems Engineering, vol. 33, no. 9, pp. 63-67, 2015.

[4] Z. Hu, "Research on urban flood emergency supplies dispatch and transportation optimization," Postgraduate thesis, Shenyang University of Technology, Shenyang, China, 2018.

[5] M.-F. Yang, Y. Lin, L. H. Ho, and W. F. Kao, "An integrated multiechelon logistics model with uncertain delivery lead time and quality unreliability," Mathematical Problems in Engineering, vol. 2016, Article ID 8494268, 13 pages, 2016.

[6] J. Jiang, J. Chen, and C. Wang, "Multi-granularity hybrid parallel network simplex algorithm for minimum-cost flow problems," The Journal of Supercomputing, vol. 76, no. 12, pp. 9800-9826, 2020.

[7] J. Wang, M. K. Lim, Y. Zhan, and X. Wang, "An intelligent logistics service system for enhancing dispatching operations in an IoT environment," Transportation Research Part E: Logistics and Transportation Review, vol. 135, p. 101886, 2020.

[8] Z. Gao, D. Wang, and H. Zhou, "Intelligent circulation system modeling using bilateral matching theory under internet of things technology," The Journal of Supercomputing, 2021.

[9] H. Wang and X. Ma, "Research on multiobjective location of urban emergency logistics under major emergencies," Mathematical Problems in Engineering, vol. 202112 pages, 2021.

[10] W. Liu, H. Xu, X. Sun, Y. Yang, and Y. Mo, "Order allocation research of logistics service supply chain with mass 
customization logistics service," Mathematical Problems in Engineering, vol. 2013, Article ID 957260, 13 pages, 2013.

[11] Y. Sun, Y. Ren, and X. Cai, "Biobjective emergency logistics scheduling model based on uncertain traffic conditions," Mathematical Problems in Engineering, vol. 202015 pages, 2020.

[12] Z.-H. Hu and J.-B. Sheu, "Post-disaster debris reverse logistics management under psychological cost minimization," Transportation Research Part B: Methodological, vol. 55, pp. 118-141, 2013.

[13] R. A. Garrido, P. Lamas, and F. J. Pino, "A stochastic programming approach for floods emergency logistics," Transportation Research Part E: Logistics and Transportation Review, vol. 75, pp. 18-31, 2015.

[14] N. Wang, Z.-P. Fan, and X. Wang, "Channel coordination in logistics service supply chain considering fairness," Mathematical Problems in Engineering, vol. 2016, Article ID 9621794, 15 pages, 2016.

[15] Y. Liu and B. Guo, "A lexicographic approach to postdisaster relief logistics planning considering fill rates and costs under uncertainty," Mathematical Problems in Engineering, vol. 201417 pages, 2014.

[16] M. Sang, Y. Ding, M. Bao, Y. Fang, and B. Lu, "Propagation dynamics model considering the characteristics of 2019nCOV and prevention-control measurements," Systems Engineering-Theory \& Practice, vol. 41, no. 1, pp. 124-133, 2021.

[17] H.-D. Lin and G.-J. Gao, "Research on the development strategy of reverse logistics of abandoned medicine in China," in Proceedings of the 2017 3rd International Forum on Energy, Environment Science and Suppliess (IFEESM 2017), Suzhou, China, October 2018.

[18] C. F. Zhu, Z. K. Zhang, and C. X. Ma, "Research on emergency logistics dynamic network based on super network," Latin American Applied Research, vol. 47, no. 1-2, pp. 11-16, 2017.

[19] L. Xu, Y. Tu, and Y. Zhang, "A grasshopper optimizationbased approach for task assignment in cloud logistics," Mathematical Problems in Engineering, vol. 2020, Article ID 3298460, 10 pages, 2020.

[20] J. Lv, Y. Zhang, and Y. Zhuang, "Research on optimization of emergency logistics capability based on smart logistics under the public health crisis," China Soft Science, no. S1, pp. 16-22, 2020.

[21] X. Li, Y. Wang, and F. Wang, "Research on improvement of emergency logistics based on application of blockchain during public health emergencies," Contemporary Economic Management, vol. 42, no. 4, pp. 57-63, 2020.

[22] D. Jin and L. Ying, "Planning improves city's immunity: a written conversation on COVID-19 breakout," City Planning Review, vol. 44, no. 2, pp. 115-136, 2020.

[23] K. Govindan, T. C. E. Cheng, N. Mishra, and N. Shukla, "Big data analytics and application for logistics and supply chain management," Transportation Research Part E: Logistics and Transportation Review, vol. 114, pp. 343-349, 2018.

[24] S. Shafqat, S. Kishwer, R. U. Rasool, J. Qadir, T. Amjad, and H. F. Ahmad, "Big data analytics enhanced healthcare systems: a review," The Journal of Supercomputing, vol. 76, no. 3, pp. 1754-1799, 2020.

[25] L. Ning, "Collaborative management of epidemic emergency supply chain dealing with COVID-19," Health Economics Research, vol. 37, no. 4, pp. 7-9, 2020.

[26] Q. Hu, J. He, and Q. Dong, "Research on emergency suppliess supply information management of medical epidemic prevention under blockchain architecture-targeted donation of
COVID-19 prevention suppliess as an example," Health Economics Research, vol. 37, no. 4, pp. 10-14, 2020.

[27] B. R. Chang, N. T. Nguyen, B. Vo, and H.-H. Hsu, "Advanced cloud computing and novel applications," Mathematical Problems in Engineering, vol. 2015, Article ID 630923, 2 pages, 2015.

[28] P. Wang, A study of information service paradigm of government procurement cloud based on value chain collaboration, $\mathrm{PhD}$ thesis, Tianjin University, Tianjin, China, 2017.

[29] J. Wang, H. Zhang, and Y. Wang, "Research on the tiered risk management mechanism of the global logistics cloud platform," Modernization of Management, vol. 39, no. 3, pp. 105-108, 2019.

[30] Lijia, "A research on intelligent logistics mode reconstruction based on big data cloud computing," China Business and Market, vol. 33, no. 2, pp. 20-29, 2019.

[31] D. Fu, S. Hu, L. Zhang, S. He, and J. Qiu, “An intelligent cloud computing of trunk logistics alliance based on blockchain and big data," The Journal of Supercomputing, 2021.

[32] Y. He and L. Ren, "Supply chain management model based on 4PL reverse logistics integration," Journal of Southeast University (Philosophy and Social Science), vol. 15, no. 4, pp. 41-45, 2013.

[33] Y. Jia, "Stochastic petri net modeling analysis of emergency resources allocation process considering reverse logistics," Journal of Safety Science and Technology, vol. 15, no. 4, pp. 12-18, 2019.

[34] Z. Chu, B. Feng, and F. Lai, "Logistics service innovation by third party logistics providers in China: aligning guanxi and organizational structure," Transportation Research Part E: Logistics and Transportation Review, vol. 118, pp. 291-307, 2018.

[35] B. Lu, Y. Wu, and C. Huang, "Research on collaboration platform for urban reverse emergency logistics union in internet of things environment," Science and Technology Management Research, vol. 33, no. 17, pp. 220-226, 2013.

[36] M. Arulprakash and R. Jebakumar, "People-centric collective intelligence: decentralized and enhanced privacy mobile crowd sensing based on blockchain," The Journal of Supercomputing, 2021.

[37] C.-Y. Chen and J.-F. Tu, "A novel cloud computing algorithm of security and privacy," Mathematical Problems in Engineering, vol. 2013, Article ID 871430, 6 pages, 2013.

[38] M. Wang, H. Lin, H. He, Z. Qing, and R. Wu, "Design and implementation of COVID-19 epidemic prevention assistant system based on spatiotemporal big data cloud platform: taking Guangzhou as an example," Bulletin of Surveying and Mapping, no. S1, pp. 198-204, 2020.

[39] Y. Wang and B. Sun, "Dynamic multi-stage allocation model of emergency suppliess for multiple disaster sites," Chinese Journal of Management Science, vol. 27, no. 10, pp. 138-147, 2019.

[40] X. Hu, "Research on optimal matching of urban emergency medical supplies under major public health events," China Journal of Highway and Transport, vol. 33, no. 11, pp. 55-64, 2020.

[41] B. Balcik, B. M. Beamon, and K. Smilowitz, "Last mile distribution in humanitarian relief," Journal of Intelligent Transportation Systems, vol. 12, no. 2, pp. 51-63, 2008.

[42] Y. Wang, "Distribution routing optimization on fresh produce-a case in Xianmatou," Postgraduate thesis, Changsha University of Science \& Technology, Changsha, China, 2014. 
[43] Z. Yuan, "Optimization of cold chain logistics path based on improved genetic algorithm," Journal of Shandong Industrial Technology, vol. 10, p. 216, 2019.

[44] C. Li, "Research on the distribution path of fresh products in City under O2O operation mode," Postgraduate thesis, Dalian Maritime University, Dalian, China, 2017.

[45] X. Q. Xue, X. P. Wang, T. Han, and J. H. Ruan, "Study on joint dispatch optimization of emergency suppliess considering traffic constraints and capacity limits," Chinese Journal of Management Science, vol. 28, no. 3, pp. 21-30, 2020.

[46] M. Zakarya and L. Gillam, "Modelling resource heterogeneities in cloud simulations and quantifying their accuracy," Simulation Modelling Practice and Theory, vol. 94, pp. 43-65, 2019.

[47] J. Liu, S. Chen, Z. Zhou, and T. Wu, "An anomaly detection algorithm of cloud platform based on self-organizing maps," Mathematical Problems in Engineering, vol. 2016, Article ID 3570305, 9 pages, 2016.

[48] X. Zhong, G. Yang, L. Li, and L. Zhong, "Clustering and correlation based collaborative filtering algorithm for cloud platform," IAENG International Journal of Computer Science, vol. 43, no. 1, 2016. 